\title{
Flash Glucose Monitoring: The Future Is Here
}

\author{
Satish K. Garg, MD ${ }^{1,2}$ and Halis Kaan Akturk, MD,,2
}

$\mathbf{W}$ E CANNOT BELIEVE that it has been more than two decades since we first evaluated real-time continuous glucose monitoring (CGM)- $\left(\right.$ GlucoWatch $\left.^{\circledR}\right)$ in patients with type 1 diabetes (T1D). The first real-time CGM (GlucoWatch), which uses a reversed iontophoresis to measure interstitial glucose, was approved to be used for $12 \mathrm{~h}$ by the Food and Drug Administration (FDA) in 1999. ${ }^{1,2}$ Since then, several advancements have led to the availability of many CGM systems MiniMed iPro ${ }^{\circledR}$, Enlite $2^{\circledR}$, Enlite Enhanced, Enlite 3 (Medtronic, Northridge, CA), DexCom STS (Short Term Sensor), Dexcom 3, 7, Gen 4 and $5^{\circledR}$ (Dexcom, San Diego, CA), and Navigator ${ }^{\circledR}$ (Abbott Diabetes Care, Alameda, CA) ${ }^{3,4}$ All of the CGMs were approved as adjunctive and needed 2-4 calibrations a day., 3 Bailey et al. highlighted the accuracy of CGMs and clinical implications of accuracy in this supplement. ${ }^{5}$ Most recently, for the first time, Dexcom Gen 5 was approved as nonadjunctive, and CGM data could be used for insulin dosing decisions, although it still needs 2 calibrations a day. ${ }^{6}$ Large, multicenter, randomized clinical trials that showed the utility of using CGM were detailed by Slattery et al. in this supplement. ${ }^{7}$ The first major breakaway came with the launch of FreeStyle Libre Pro ${ }^{\mathrm{TM}}$ (professional) or personal-a patch glucose sensor, needing no calibration (factory calibrated) that lasts for 14 days. 8,9

FreeStyle Libre ${ }^{\mathrm{TM}}$ professional or personal, commonly referred to as "flash glucose monitoring" system, where the data are available on demand at any time during 14 days and needs no calibration during its use. Only FreeStyle Libre Pro is currently approved by FDA for professional use. ${ }^{8}$ Wright et al. emphasized the benefits of flash glucose monitoring professional use with real case series in this supplement. ${ }^{10}$ The flash glucose monitoring has had a significant uptake in European countries wherever it has been made available. In fact, more recently, I had two of my patients who bought their flash glucose monitoring personal in Europe, and they were very "impressed" with its accuracy, ease of use, and liked that flash glucose monitoring did not need any calibrations. There are many reasons for early success and rapid uptake of flash glucose monitoring. These include the following:
- Lowest cost of a CGM system (flash glucose monitoring) ${ }^{11}$

- No calibration needed ${ }^{12}$ (I can't emphasize this enough as it is a big deal for most patients)

- First 14-day factory-calibrated flash glucose monitoring $^{11,12}$

- Reliable and accurate data available on demand throughout its use 9

- Similar (lower) MARD (mean absolute relative difference) throughout 14 days of use $\mathrm{e}^{11,13}$

The features that distinguish flash glucose monitoring from CGM include (1) no alerts or alarms. Many patients are fed up with the alarms from CGM systems (several of them "false") and get an "alarm fatigue" and thus have adopted flash glucose monitoring gladly ${ }^{14}$; (2) the data are recorded continuously as with other CGMs; however, they are only available on demand for 14 days and can be downloaded; (3) the adoption of ambulatory glucose profile (AGP) in the downloaded data has been well validated in the literature, and both patients and providers can visualize the data in a simple and standardized way. ${ }^{15}$

With new technologies, we have more accurate day to day assessments of the patients with diabetes especially as it relates to hypo- and hyperglycemia. As described by Wright et al. in this supplement, other parameters in diabetes care follow-up such as glycemic variability may also contribute to many adverse events associated with diabetes. ${ }^{16-18}$ Using CGM or flash glucose monitoring for the patients who have high glycemic variability was highlighted by Ajjan et al. in this supplement. ${ }^{19}$

Concomitant use of new medications such as glucagon-like peptide-1 analogues and sodium-glucose cotransporter inhibitors with insulin in type 2 diabetes (T2D) opened a new era for insulin dose adjustments. Rather than waiting for the next A1c result to determine the effect of the "add on," medications and/or dose adjustments can be made by personal or professional use of CGM/flash glucose monitoring technologies. Patients who especially use high doses of insulin with an insulin pump or multiple daily injections and experience frequent hypo- and hyperglycemia also may take advantage of availability of "data on demand" from CGM and

\footnotetext{
${ }^{1}$ University of Colorado, Denver School of Medicine, Aurora, Colorado.

${ }^{2}$ Barbara Davis Center for Diabetes - Adult Clinic, University of Colorado Anschutz Medical Campus, Aurora, Colorado.
} 
flash glucose monitoring. ${ }^{20}$ As described by Carlson et al. in this supplement, AGP with CGM or flash glucose monitoring use in adults with T2D has significant benefits. ${ }^{21}$

CGM and flash glucose monitoring use in the pediatric population is another hot topic. Prevention of hypoglycemia is important not only for pediatric patients with T1D but also other associated disorders that may cause hypoglycemia such as adrenal insufficiency, glycogen storage disorders, and cystic fibrosis. Several studies showed clinical benefits of flash glucose monitoring use in pediatric patients with T1D. ${ }^{22-24}$ The clinical implications of CGM use to prevent hypoglycemia in children with T1D and other metabolic disorders were highlighted in this supplement by Lal et al. ${ }^{25}$

We hope that flash glucose monitoring (FreeStyle Libre personal) will be made available soon in the United States after approval by the FDA. We also hope that it is approved as "nonadjunctive," since most providers and patients do not use current CGMs as adjunctive. There is enough literature available highlighting the accuracy and safety of flash glucose monitoring personal use as a stand-alone system, just like CGMs. ${ }^{4,26-31}$

Future developments in flash glucose monitoring may include the availability of "adjustable and predictable" alerts and alarms and data made available on a mobile phone (so that patients do not need to carry another device). ${ }^{32}$ Early versions of FreeStyle Libre link are available in Europe through an application on Android phones. ${ }^{33}$ Last but not least, flash glucose monitoring data may become available as "continuous" like CGMs and by using Bluetooth technology, data could be made available on the pumps or smart phones and possibly be used to drive insulin delivery like in the artificial pancreas. ${ }^{32,34,35}$

We thank Abbott Diabetes Care for thinking "outside the box" and launching the first no calibration (factory calibrated) 14-day on-demand sensor. The science behind the factory calibration of flash glucose monitoring was discussed in detail by Hoss et al. in this supplement. ${ }^{36}$ We hope you enjoy reading this supplement on flash glucose monitoring and want to thank Abbott for sponsoring the supplement.

Patients and providers were always asking for such a product. We think the future of CGM and flash glucose monitoring is bright with all the ongoing research that is likely to impact lives of people with diabetes positively and hopefully reduce "overall diabetes burden."

\section{Author Disclosure Statement}

No competing financial interests exist.

\section{References:}

1. Garg SK, Potts RO, Ackerman NR, et al.: Correlation of fingerstick blood glucose measurements with GlucoWatch Biographer results in young subjects with type 1 diabetes. Diabetes Care 1999;22:1708-1714.

2. Tamada JA, Garg S, Jovanovic L, et al.: Non-invasive glucose monitoring: comprehensive clinical results. Cygnus Research Team. JAMA 1999;282:1839-1844.

3. Garg SK, Akturk HK: The future of continuous glucose monitoring. Diabetes Technol Ther 2017;19(Suppl 3):S-1-S-2.

4. Mazze RS: Acceptance of FGM or CGM in clinical decision-making and patient preference: where do we go from here? Diabetes Technol Ther 2017;19:142-144.
5. Bailey T: Clinical implications of accuracy measurements of continuous glucose sensors. Diabetes Technol Ther 2017; 19(Suppl 2):S-51-S-54.

6. U.S. Food and Drug Administration: Approval Order: Dexcom G5 Mobile Continuous Glucose Monitoring System. PI20005. Silver Spring, MD: Department of Health and Human Services, 2016.

7. Slattery D, Choudhary P: Clinical use of glucose monitoring in adults with type 1 diabetes. Diabetes Technol Ther 2017;19(Suppl 2):S-55-S-61.

8. U.S. Food and Drug Administration: Approval Order: Freestyle Libre Pro Flash Glucose Monitoring System. PI50021. Silver Spring, MD: Department of Health and Human Services, 2016.

9. Bailey T, Bode BW, Christiansen MP, et al.: The performance and usability of a factory-calibrated flash glucose monitoring system. Diabetes Technol Ther 2015;17:787-794.

10. Wright Jr EE, Gavin III JR: Clinical use of professional continuous glucose monitoring. Diabetes Technol Ther 2017;19(Suppl 2):S-12-S-15.

11. Ólafsdóttir AF, Attvall S, Sandgren U, et al.: A clinical trial of the accuracy and treatment experience of the flash glucose monitor FreeStyle Libre in adults with type 1 diabetes. Diabetes Technol Ther 2017;19:164-172.

12. Hoss U, Budiman ES, Liu H, Christiansen MP: Feasibility of factory calibration for subcutaneous glucose sensors in subjects with diabetes. J Diabetes Sci Technol 2014;8: 89-94.

13. Hoss U, Budiman ES, Liu H, Christiansen MP: Continuous glucose monitoring in the subcutaneous tissue over a 14-day sensor wear period. J Diabetes Sci Technol 2013;7:1210-1219.

14. Shivers JP, Mackowiak L, Anhalt H, Zisser H: "Turn it off!": diabetes device alarm fatigue considerations for the present and the future. J Diabetes Sci Technol 2013;7: 789-794.

15. Forlenza GP, Pyle LL, Maahs DM, Dunn TC: Ambulatory glucose profile analysis of the juvenile diabetes research foundation continuous glucose monitoring datasetApplications to the pediatric diabetes population. Pediatr Diabetes 2016. DOI:10.1111/pedi.12474.

16. Wright LAC, Hirsch IB: Metrics beyond hemoglobin A1c in diabetes management: time in range, hypoglycemia, and other parameters. Diabetes Technol Ther 2017;19(Suppl 2):S-16-S-26.

17. Gorst C, Kwok CS, Aslam S, et al.: Long-term glycemic variability and risk of adverse outcomes: a systematic review and meta-analysis. Diabetes Care 2015;38:2354-2369.

18. Mendez CE, Mok KT, Ata A, et al.: Increased glycemic variability is independently associated with length of stay and mortality in noncritically ill hospitalized patients. Diabetes Care 2013;36:4091-4097.

19. Ajjan RA: How can we realize the clinical benefits of continuous glucose monitoring? Diabetes Technol Ther 2017;19(Suppl 2):S-27-S-36.

20. Zick R, Petersen B, Richter M, Haug C: Comparison of continuous blood glucose measurement with conventional documentation of hypoglycemia in patients with type 2 diabetes on multiple daily insulin injection therapy. Diabetes Technol Ther 2007;9:483-492.

21. Carlson A, Mullen DM, Bergenstal RM: Clinical use of continuous glucose monitoring in adults with type 2 diabetes. Diabetes Technol Ther 2017;19(Suppl 2):S-4-S-11.

22. Edge J, Acerini C, Campbell F, et al.: An alternative sensor-based method for glucose monitoring in children 
and young people with diabetes. Arch Dis Child 2017 Jan 30 doi:10.1136/archdischild-2016-311530.

23. Walter M: Type 1 diabetes in children: flash glucose monitoring for a better diabetes management. Diabetes Aktuell 2016;14:358.

24. Hulse A, Rai S, Prasanna-Kumar KM: Evaluation of accuracy of ambulatory glucose profile in an outpatient setting in children with type 1 diabetes. Indian $\mathrm{J}$ Endocrinol Metab 2016;20:643-647.

25. Lal RA, Maahs DM: Clinical use of CGM in pediatrics. Diabetes Technol Ther 2017;19(Suppl 2):S-37-S-43.

26. Fonseca VA, Grunsberger G, Anhalt H, et al.: Continuous glucose monitoring: a consensus statement by the American Association of Clinical Endocrinologists and American College of Endocrinology. Endocr Pract 2016;22:10081021.

27. Ji L, Guo X, Guo L, et al.: A multicenter evaluation of the performance and usability of a novel glucose monitoring system in Chinese adults with diabetes. J Diabetes Sci Technol 2017;11:290-295.

28. Bonora B, Maran A, Ciciliot S, et al.: Head-to-head comparison between flash and continuous glucose monitoring systems in outpatients with type 1 diabetes. J Endocrinol Invest 2016;39:1391-1399.

29. Bolinder J, Weitgasser R, Antuna R, et al.: Randomised controlled study to evaluate the impact of novel glucosesensing technology on hypoglycemia in type 1 diabetes. The Lancet 2016;388:2254-2263.

30. Distiller LA, Cranston I, Mazze R: First clinical experience with FreeStyle ${ }^{\circledR}$ Libre Pro Flash Glucose Monitoring
(FGM): characterizing glycemic control with Ambulatory Glucose Profile (AGP) analysis in South Africa. J Diabetes Sci Technol 2016;10:1294-1302.

31. Ish-Shalom M, Wainstein J, Raz I, Mosenzon O: Improvement in glucose control in difficult-to-control patients with diabetes using a novel Flash Glucose Monitoring device. J Diabetes Sci Technol 2016;5:1572-1583.

32. Shah VN, Garg SK: Managing diabetes in the digital age. Clin Diabetes Endocrinol 2015;1:1-7.

33. European Economic Area: Approval: Freestyle Libre Flash Glucose Monitoring System CE Mark (Conformite Europeenne). Abbott Laboratories Ltd. Press release: Abbott receives CE mark for Freestyle Libre, 2014.

34. Shah VN, Shoskes A, Tawfik B, Garg SK: Closed-loop system in the management of diabetes: past, present and future. Diabetes Technol Ther 2014;16:477-490.

35. Rodbard D: Continous glucose monitoring: A review of recent studies demonstrating improved glycemic outcomes. Diabetes Technol Ther 2017;19(Suppl 3):S-25-S-37.

36. Hoss U, Budiman ES: Factory-calibrated continuous glucose sensors: the science behind the technology. Diabetes Technol Ther 2017;9(Suppl 2):S-44-S-54.

Address correspondence to: Satish K. Garg, MD Barbara Davis Center for Diabetes - Adult Clinic 1775 Aurora Court, A140 Aurora, CO 80045

E-mail: satish.garg@ucdenver.edu 